\title{
Effect of Exogenous Carbon on Movement of Simazine and 2,4-D in Soils
}

\author{
L. Cox, A. Cecchi, R. Celis, M. C. Hermosín, W. C. Koskinen, and J. Cornejo*
}

\begin{abstract}
Organic amendment $(\mathrm{OA})$ addition is an agricultural practice that can greatly affect pesticide behavior in soil. The influence of three OAs, consisting of a liquid amendment (LOA), solid (SOA) humic amendment, and a solid urban waste (SUW), on sorption, persistence, and leaching potential of simazine (2-chloro-4,6-bis (ethylamino)-striazine) and 2,4-D (2,4-dichlorophenoxyacetic acid) in a sandy soil (P2) has been investigated. The OAs were added to $\mathrm{P} 2$ at a rate of $5 \%$ (w/w). Sorption was studied using the batch equilibration technique, degradation by incubations at $20^{\circ} \mathrm{C}$ and $-0.33 \mathrm{kPa}$ moisture content, and leaching using handpacked soil columns. Simazine sorption increased in the order of P2 $\leq \mathbf{P 2}+$ LOA $<$ P2 + SUW $<$ P2 + S OA. The herbicide, 2,4-D, did not sorb on P2 soil, but in amended soils sorption increased in the same order as simazine. The lower sorption of both herbicides in P2 + LOA as compared with P2 + SOA and P2 + SUW is attributed to higher dissolved organic matter (DOM) content of LOA. Simazine's half-life was reduced upon amendment. Degradation of 2,4-D followed a sigmoidal rate in P2, P2 + SOA, and P2 + SUW, but not in P2 + LOA, in which 2,4-D persistence was much higher. The higher stability of 2,4-D in P2 + LOA has been attributed to 2,4-D-dissoved organic $\mathrm{C}$ interactions. Leaching studies indicate that degradation affects movement to a higher extent than sorption, specially in the case of 2,4-D in P2 + LOA soil, in which the amounts leached are much higher than those in unamended soil. In the case of simazine and P2 + SUW soil, greater reduction in large-size conducting pores upon amendment, as revealed in $\mathrm{Hg}$ porosimetry studies, resulted in a greater reduction of leaching than that suggested from the small differences in sorption and degradation between P2 and P2 + SUW soil.
\end{abstract}

$\mathrm{P}$ ESTICIDES are recognized as a source of potential adverse environmental impacts (nonpoint and point pollution) and their presence in surface and ground waters has grown considerably (Wauchope, 1978; Ritter et al., 1994). Soil applied herbicides reach surface and ground waters by the losses associated with runoff and leaching processes (Beck et al., 1993). These losses are attenuated by the natural process of sorption, since degradation, transport, and biological activity of pesticides are greatly influenced by sorption on soil constituents, in particular soil organic matter (Chiou, 1989; Koskinen and Harper, 1990).

Organic amendments, commonly used to enrich low organic matter content soils, can modify surfaces of soils and subsurface materials increasing sorption potential and reducing pesticide contamination of ground water (Zsolnay, 1992; Barriuso et al., 1996; Cox et al., 1997). The addition of OAs to the soil surface is also known to

L. Cox, R. Celis, M. C. Hermosin, and J. Cornejo, Instituto de Recursos Naturales y Agrobiología de Sevilla, CSIC, P.O. Box 1052, 41080 Sevilla, Spain; A. Cecchi, Dep. Soil, Water \& Climate, Univ. Minnesota, St. Paul, MN 55108; W.C. Koskinen, USDA-ARS, Soil and Water Management Research Unit, 1991 Upper Buford Cir. Rm 439, St. Paul, MN 55108. Received 28 Sept. 2000. *Corresponding Author (cornejo@irnase.csic.es).

Published in Soil Sci. Soc. Am. J. 65:1688-1695 (2001). stimulate soil microbial activity, which could potentially lead to accelerated degradation, reducing the total amount of chemical available for leaching and to injure crops planted in rotation (Felsot and Dzantor, 1995; Topp et al., 1996; Cox et al., 1997). Accordingly, the study of the influence of OA on pesticide behavior in soil is of great interest, specially when it is an issue very seldom considered when making the decision of fertilizing soil or disposing organic wastes; other aspects being considered are nutritional ones, risk of nitrate leaching, or accumulation of heavy metals in soil.

The incorporation of OAs in soils introduces both solid organic matter and DOC. Dissolved organic C has been shown to reduce pesticide sorption because of DOC-pesticide interactions and competition between DOC molecules and pesticide molecules for sorption sites (Lee et al., 1990; Barriuso et al., 1992; Businelli, 1997; Celis et al., 1998a; Cox et al., 2000). This decrease in sorption would enhance transport and increase the risk of ground water contamination. Consequently, the effect of OA addition on pesticide behavior is not easy to predict, especially when liquid amendments are applied or when DOM concentrations resulting from the $\mathrm{OA}$ are high.

The aim of this study was to assess the influence of OA (commercial LOA, SOA, and a SUW) on sorption and degradation of pesticides, and the potential applicability of these amendments for reducing pesticide leaching in soil. We have selected two herbicides widely used in agriculture, simazine and 2,4-D. Simazine is relatively persistent and, despite its low water solubility $(5 \mathrm{mg}$ $\mathrm{L}^{-1}$ ), its significant nonpoint source of water contamination is reported (Wauchope, 1978; Agbekodo et al. 1996). The anionic herbicide, 2,4-D is of relatively high water solubility $\left(620 \mathrm{mg} \mathrm{L}^{-1}\right)$ and, as other anionic contaminants, its presence in ground water is a concern because anionic contaminants are weakly retained by most soil or sediment components (Goodrich et al., 1991; Hermosín and Cornejo, 1993).

\section{MATERIALS AND METHODS}

Herbicides, Soils, and Amendments

Simazine is a colorless solid with a melting point of $226^{\circ} \mathrm{C}$, a vapor pressure of $810 \mathrm{nPa}$, and a water solubility $\left(20^{\circ} \mathrm{C}\right)$ of $25 \mu \mathrm{M}$ (Worthing and Hance, 1991). As other chloros-triazines, the hydroxylated and $N$-dealkylated derivatives are, respectively, major chemical and biological degradation products of simazine (Khan, 1980). High purity (>98\%) simazine was purchased from Riedel-de Haën (Germany). The herb-

Abbreviations: BTC, breakthrough curve; Ce, equilibrium concentration; $\mathrm{Ci}$, initial concentrations; $\mathrm{Cs}$, solid concentration; DOC, dissolved organic C; DOM, dissolved organic matter; HPLC, high performance chromatography; LOA, liquid organic amendment, OA, organic amendment; P2, sandy soil; SOA, solid organic amendment; SUW, solid urban waste. 
Table 1. Physicochemical properties of the liquid organic amendment (LOA), solid organic amendment (SOA), and solid urban waste (SUW).

\begin{tabular}{|c|c|c|c|}
\hline Parameter & LOA & SOA & SUW \\
\hline pH (1:5) & 5.09 & 9.40 & 7.82 \\
\hline Dry matter, $\mathbf{g ~ k g}^{-1}$ & 312.0 & - & - \\
\hline Organic C, $\mathbf{g ~ k g}^{-1}$ & 149.4 & 183.1 & 161.0 \\
\hline Dissolved organic $\mathrm{C}, \mathrm{mg}^{-1}$ & 68000 & 2000 & 400 \\
\hline $\mathbf{C} / \mathbf{N}$ & 13.8 & 15.8 & 16.5 \\
\hline N Kjeldahl, $\mathbf{g ~ k g}^{-1}$ & 9.3 & 10 & 8.4 \\
\hline $\mathbf{P}, \mathbf{P}_{2} \mathbf{O}_{5} \mathbf{g ~ k g}^{-1}$ & 2.1 & 8.7 & 9.8 \\
\hline $\mathbf{K}, \mathbf{K}_{2} \mathbf{O} \mathbf{g} \mathbf{k g}^{-1}$ & 22 & 32 & 4.8 \\
\hline $\mathrm{Ca}, \mathrm{g} \mathrm{kg}^{-1}$ & 2.7 & 65 & 45.1 \\
\hline $\mathbf{M g}, \mathbf{g ~ k g}^{-1}$ & 1.0 & 13 & $\begin{array}{r}45.1 \\
2.8\end{array}$ \\
\hline $\mathrm{Fe}, \mathrm{mg} \mathrm{kg}^{-1}$ & 3610 & 10000 & 11400 \\
\hline $\mathrm{Cu}, \mathrm{mg} \mathrm{kg}^{-1}$ & 25 & 70 & 261 \\
\hline Mn, mg kg-1 & 38 & 240 & 182 \\
\hline $\mathrm{Zn}, \mathrm{mg} \mathrm{kg}^{-1}$ & 18 & 57 & 447 \\
\hline $\mathrm{Cr}, \mathrm{mg} \mathrm{kg}^{-1}$ & $<5$ & $<5$ & 83 \\
\hline $\mathrm{Ni}, \mathbf{m g} \mathbf{k g}^{-1}$ & $<5$ & $<5$ & 25 \\
\hline Cd, mg kg & $<1$ & $<1$ & 1 \\
\hline Pb, mg kg $\mathbf{k g}^{-1}$ & $<5$ & $<5$ & 231 \\
\hline
\end{tabular}

icide, 2,4-D, is a colorless solid with a melting point of $140.5^{\circ} \mathrm{C}$, a vapor pressure of $53 \mathrm{~Pa}$, and a water solubility $\left(25^{\circ} \mathrm{C}\right)$ of $2.8 \mathrm{mM}$ (Worthing and Hance, 1991). The major metabolic reactions associated with phenoxyalcanoic acids, such as 2,4-D, are ring hydroxylation, cleavage of the ether linkage, ring cleavage, and dehalogenation (Khan, 1980). High purity (>98\%) 2,4-D was purchased from Sigma (St. Louis, MO).

The top $50 \mathrm{~cm}$ of the soil profile P2 was sampled, air dried, and sieved to pass a 2-mm mesh screen. In the laboratory, the three OAs (LOA, SOA, and SUW) were added to the original soil at the rate of $50 \mathrm{~g}$ of OA per $\mathrm{kg}$ of air-dried soil. The rates of OA applied are only slightly higher than the realistic amounts that growers add, and fall within normal application rates for wastes such as sewage sludges (Sloan et al. 1998). The SOA and LOA amendments are two commercial amendments derived from the composted solid waste of the olive-mill process and the corresponding liquid residue, respectively. The SUW was a composted municipal waste from Huelva, Spain. Spectroscopic study of the organic C of these OAs (Cox et al., 2000 ) indicated that LOA contains great amounts of relatively nonhumified material. On the contrary, SOA contains the highest amounts of highly humified material; the maximal intensity of SOA is shifted toward the red region indicating a more complicated, presumably aromatic, nature of this $\mathrm{OA}$ compared with LOA. The grade of humification of SUW is between that of LOA and SOA (Cox et al., 2000).

Amended soils were thoroughly mixed and air dried. Some physicochemical properties of the OAs are given in Table 1, whereas physicochemical properties of the original (unamended) Soil P2 and amended soils are given in Table 2. Organic matter of the soil samples and amendments were determined by dichromate oxidation (Nelson and Sommers, 1982), soil $\mathrm{pH}$ was determined in a $1: 2(\mathrm{w} / \mathrm{w})$ soil/deionized water mixture, texture by sedimentation, and clay mineralogy by x-ray diffraction on oriented specimens.

\section{Dissolved Organic Carbon Measurements and Dialysis Experiment}

To determine the amount of DOC of soil and OAs, $15 \mathrm{~g}$ of original soil, $\mathrm{P} 2$, amended soils, and solid OA (SOA and SUW) were treated with $30 \mathrm{~mL}$ of a $4 \mathrm{~m} M \mathrm{CaCl}_{2}$ solution, shaken for $10 \mathrm{~min}$, centrifuged at $31000 \times \mathrm{g}$ for $15 \mathrm{~min}$, filtered on polycarbonate filters $(0.45 \mu \mathrm{m}$ pore diam.), and extracts diluted with bidistilled water. The LOA amendment was also diluted with doubly distilled water. The concentration
Table 2. Selected physicochemical properties of the unamended soil (P2) and soil amended with $5 \%(w / w)$ of liquid organic amendment (LOA), solid organic amendment (SOA), and solid urban waste (SUW).

\begin{tabular}{|c|c|c|c|c|c|c|}
\hline Sample & pH & $\begin{array}{c}\text { Total } \\
\text { organic C }\end{array}$ & DOC & Sand & Clay $(\mathbf{I}, \mathbf{K}, \mathbf{M}) \dagger$ & $\mathrm{Fe}_{2} \mathrm{O}_{3}$ \\
\hline & & $\mathrm{g} \mathrm{kg}^{-1}$ & $\mathbf{m g ~ L ^ { - 1 }}$ & & $\mathrm{g} \mathrm{kg}^{-1}$ & \\
\hline $\mathbf{P 2}$ & 7.1 & 6.6 & 20 & 754 & $164(600,200,200)$ & 43 \\
\hline $\mathbf{P 2}+\mathbf{L O A}$ & 6.5 & $9.2 *$ & $1300 * *$ & - & - & - \\
\hline $\mathbf{P 2}+$ SOA & 7.7 & 8.8* & $100 * *$ & - & - & - \\
\hline $\mathbf{P 2}+$ SUW & 7.7 & 7.8* & 25 & & & \\
\hline
\end{tabular}

* Significant at the 0.05 probability level. ** Significant at the 0.01 probability level. **** Significant at the 0.001 probability level.

$\dagger \mathbf{I}=$ Illite; $\mathbf{K}=$ Kaolinite; $\mathbf{M}=$ Montmorillonite.

of DOC in the extracts was measured in a Shimadzu 5050 Total Organic Carbon Analyzer (Shimadzu, Columbia, MD).

A simple device was designed to detect herbicide-DOC in solution in the case of LOA. Pure LOA $(2 \mathrm{~mL})$ was introduced in a dialysis membrane with molecular cutoff of $1200 \mathrm{Da}$ and dialyzed in a $10-\mathrm{mm}$ i.d. by $120-\mathrm{mm} \mathrm{L}$ test tube against $3 \mathrm{~mL}$ of a $10 \mu \mathrm{M}$ aqueous herbicide solution. After a $72 \mathrm{~h}$ equilibration period, herbicide concentration was analyzed inside and outside the dialysis membrane as described below.

\section{Sorption Studies}

Sorption studies were performed using the batch equilibration procedure. Duplicate samples of $5 \mathrm{~g}$ of each soil were treated with $10 \mathrm{~mL}$ of simazine solutions of initial concentrations $(\mathrm{Ci})$ ranging from 0.5 to $10 \mu M$, or $10 \mathrm{~mL}$ of $2,4-\mathrm{D}$ solutions of $\mathrm{Ci}$ ranging from 5 to $100 \mu \mathrm{M}$. The suspensions were shaken at $20 \pm 2^{\circ} \mathrm{C}$ for $24 \mathrm{~h}$ and then centrifuged at $31000 \times g$ at the same temperature. Previously, it was determined that equilibrium was reached in $<24 \mathrm{~h}$, and that no measurable degradation occurred during this period. Sorption controls (10 $\mathrm{mL}$ of solution without soil) were also shaken for $24 \mathrm{~h}$ and recoveries were close to $100 \%$. Equilibrium concentrations (Ce) in the supernatants were determined by high performance liquid chromatography (HPLC) under the following conditions: Nova-Pack column (Waters Corp., Milford, MA), $150 \mathrm{~mm}$ length by $3.9 \mathrm{~mm}$ i.d.; column packing, C18; flow rate,

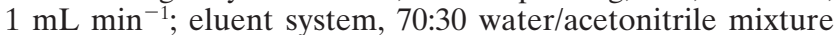
for simazine and 55:45 diluted $\mathrm{H}_{3} \mathrm{PO}_{4}(\mathrm{pH}=2.0) /$ methanol for 2,4-D; UV detection at $230 \mathrm{~nm}$. Differences between $\mathrm{Ci}$ and Ce were assumed to be the amounts sorbed by the solid phase (Cs). Sorption isotherms were fit to the Freundlich equation and sorption coefficients, $K_{\mathrm{f}}$ and $1 / n_{\mathrm{f}}$, calculated. Sorption coefficients, $K_{\mathrm{f}}$ normalized to organic C content of the soils $\left(K_{\mathrm{oc}}\right)$ were also calculated.

\section{Incubation Studies}

Duplicate amounts (400 g) of each soil (P2, P2 + LOA, $\mathrm{P} 2+\mathrm{SOA}$, and $\mathrm{P} 2+\mathrm{SUW})$ were treated with a $100 \mathrm{mg} \mathrm{L}^{-1}$ ethanol solution of simazine or a $100 \mathrm{mg} \mathrm{L}^{-1}$ aqueous solution of 2,4-D to give a concentration of $5 \mathrm{mg} \mathrm{kg}^{-1}$ and $2.3 \mathrm{mg}$ $\mathrm{kg}^{-1}$ of dry soil, respectively. Maximum application rates of simazine and 2,4-D are 5 and $2.3 \mathrm{~kg} \mathrm{ha}^{-1}$, respectively. Moisture content was adjusted to $-0.33 \mathrm{kPa}$, and soil samples were thoroughly mixed by passing them through a sieve at least four times. Herbicide treated soil samples were transferred to kilner jars where they were incubated at $20^{\circ} \mathrm{C}$ for $28 \mathrm{~d}$. Moisture contents were maintained at a constant level throughout the experiment by adding distilled water as necessary, soils were sampled periodically and frozen till analyzed. Herbicide residues were extracted by shaking $10 \mathrm{~g}$ of soil with $20 \mathrm{~mL}$ 
of methanol (simazine) or 55:45 diluted $\mathrm{H}_{3} \mathrm{PO}_{4}(\mathrm{pH}=2.0) /$ methanol $(2,4-\mathrm{D})$ for $24 \mathrm{~h}$ and extracts were analyzed by HPLC under the conditions described above. Recoveries were $>90 \%$ for both herbicides. To calculate half-lives from dissipation curves, we have assumed that the amount of simazine or 2,4-D not extracted with methanol (simazine) or acidified water + methanol mixture (2,4-D) is degraded, although a fraction of the herbicides could be irreversibly or strongly bound to soil, which can be considered not readily available (Cox et al., 1998).

\section{Soil Column Studies}

Herbicide leaching was studied under near-saturated conditions using 30 by $5 \mathrm{~cm}$ methacrylate columns made up of six 5 -cm long sections sealed with silicon. The top ring was filled with sea sand and the bottom ring with sea sand plus glass wool, to minimize losses of soil, and contamination of leachate with soil particles. The other four rings were handpacked with $520 \mathrm{~g}$ of soil. Columns were saturated with $0.01 \mathrm{M} \mathrm{CaCl}_{2}$ and allowed to drain for $24 \mathrm{~h}$. After the soil columns were saturated, $\sim 1 \mathrm{~g}$ of soil was removed and the distribution of pore radii of soil samples from 40 to $3.7 \times 10^{-3} \mu \mathrm{m}$ was determined in duplicates using a Carlo Erba $2000 \mathrm{Hg}$ depression and intrusion porosimeter(Carlo Erba, Milan, Italy). A 0.5-g subsample of each soil was heated at $90^{\circ} \mathrm{C}$ for $24 \mathrm{~h}$ and then outgassed at room temperature for $30 \mathrm{~min}$. A value for the surface tension of $\mathrm{Hg}$ of $0.48 \mathrm{~N} \mathrm{~m}^{-1}$ and a contact angle on soils of $141.3^{\circ}$ was used with the Laplace equation assuming cylindrical pores in the calculations.

The amounts of herbicide corresponding to an application rate of 5 (simazine) or 2.3 (2,4-D) $\mathrm{kg} \mathrm{ha}^{-1}$ were applied to the top of triplicate saturated columns as a methanol solution and left the methanol evaporate. Twenty four hours after herbicide application, columns were leached with $0.01 M$ $\mathrm{CaCl}_{2}$, which was applied at a rate of $50 \mathrm{~mL} \mathrm{~d}^{-1}$. Leachates were collected daily for $20 \mathrm{~d}$, filtered with $0.22 \mu \mathrm{m}$ pore-size filters, and analyzed directly by HPLC for their herbicide concentration as described earlier.

\section{RESULTS AND DISCUSSION}

\section{Dissolved Organic Carbon of Amendments and Amended Soils}

Total organic matter contents among OAs and among amended soils are very similar, although there were large differences in DOC content (Tables 1 and 2). Dissolved organic $\mathrm{C}$ of the OAs and amended soils decrease in the order LOA $\gg$ SOA $>$ SUW. The association of DOC and of OA to P2 soil was high for LOA $(60 \%)$ but very low for SOA and SUW; nearly $100 \%$ of the DOC of the SOA and SUW did not associate to P2. Previous studies have indicated that LOA contains great amounts of relatively nonhumified material with high affinity for montmorillonite (Cox et al., 2000), which represents $20 \%$ of the clay fraction of the $\mathrm{P} 2$ soil (Table 2). In contrast, the DOC of SOA and SUW amendments contain high amounts of highly humified material (Cox et al., 2000), which appears to associate to soil to a slightly lesser extent. On the other hand, results from the dialysis experiment indicated that the DOC from LOA associates with 2,4-D but not with simazine; 2,4-D concentration inside the dialysis membrane (with DOC from LOA) was $10 \%$ higher than outside, whereas sima-
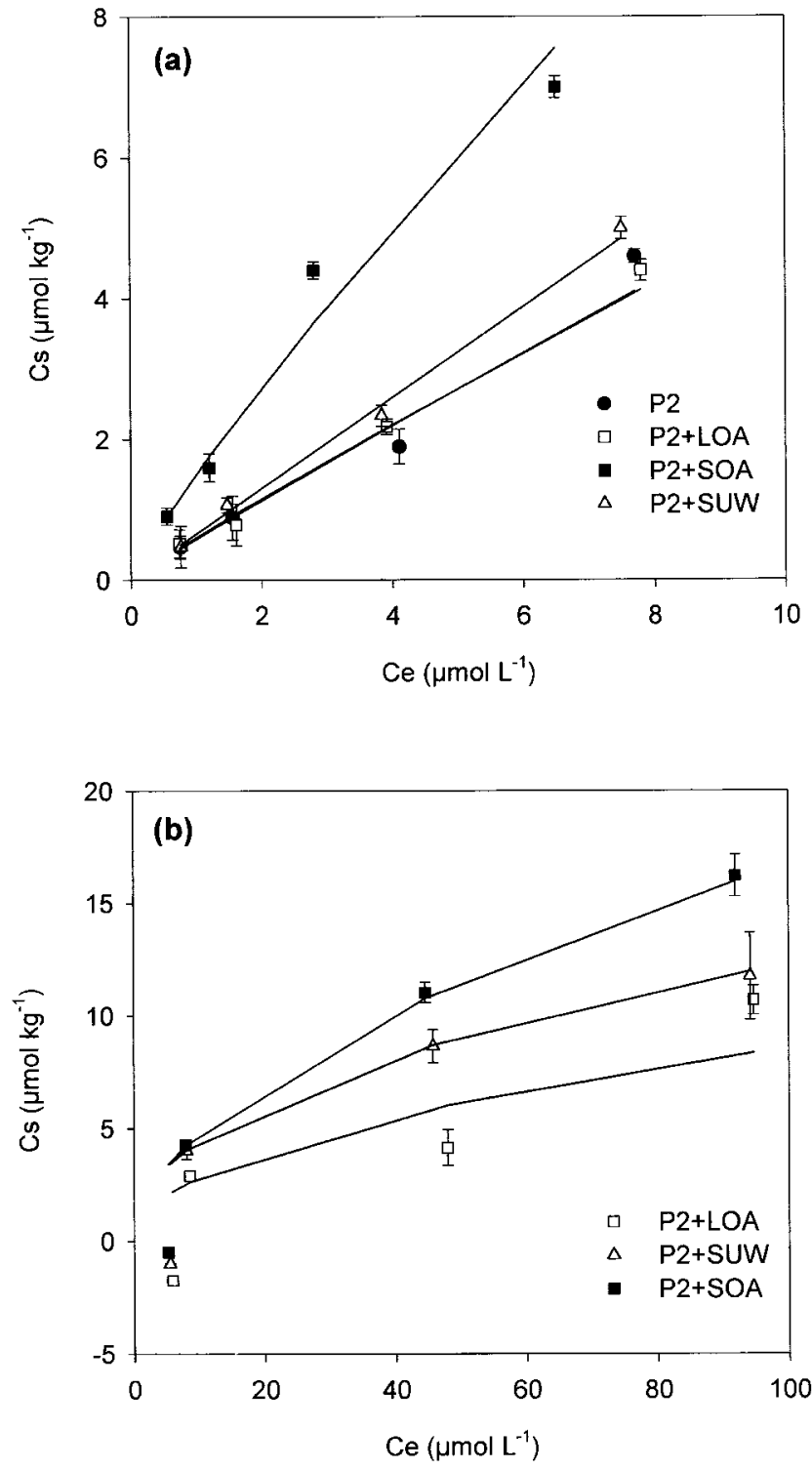

Fig. 1. (a) Simazine sorption isotherms on unamended sandy soil (Soil P2) and amended sandy soil plus liquid organic amendment (P2 + LOA), sandy soil plus solid organic amendment (P2 + SOA), and sandy soil plus solid urban waste (P2 + SUW) and (b) 2,4-D sorption isotherms on P2 + LOA, P2 + SOA, and P2 + SUW. Symbols are experimental data points, wheras lines are the Freundlick-fit sorption isotherms.

zine concentrations inside and outside the dialysis membrane were identical.

\section{Sorption Studies}

Sorption of simazine on Soil P2 greatly increased upon amendment with SOA, whereas there was a slight increase in the case of SUW amended soil, and no significant differences between sorption on P2 + LOA and on original unamended soil (Fig. 1a). Isotherms are C-type ( $1 / n_{\mathrm{f}}$ close to 1$)$, indicating that simazine sorption in original and amended soils is mainly a partitioning mechanism between solid organic matter and solution, without an apparent limit of sorption (Giles et al., 1960). Sorption isotherms were fit to the Freundlich equation 
Table 3. Freundlich sorption coefficients for simazine and 2,4-D in the unamended P2 soil and amended soils, P2 soil plus liquid organic amendment (P2 + LOA), P2 soil plus solid organic amendment (P2 + SOA), and P2 soil plus solid urban waste (P2 + SUW).

\begin{tabular}{|c|c|c|c|c|c|c|c|c|}
\hline \multirow[b]{2}{*}{ Soil } & \multicolumn{4}{|c|}{ Simazine } & \multicolumn{4}{|c|}{ 2,4-D } \\
\hline & $K_{\mathrm{f}}$ & $1 / n_{\mathrm{f}}$ & $R^{2}$ & $K_{\mathrm{oc}}$ & $K_{\mathrm{f}}$ & $1 / n_{\mathrm{f}}$ & $R^{2}$ & $K_{\text {oc }}$ \\
\hline $\mathbf{P 2}$ & $0.59(0.53-0.65) \dagger$ & $0.95 \pm 0.08$ & 0.98 & 89 & $-\ddagger$ & - & - & - \\
\hline $\mathbf{P 2}+\mathbf{L O A}$ & $0.61(0.54-0.68)$ & $0.93 \pm 0.09$ & 0.98 & 66 & $0.94(0.36-1.41)$ & $0.48 \pm 0.26$ & 0.72 & 102 \\
\hline $\mathbf{P 2}+\mathbf{S O A}$ & $1.51 *(1.38-1.66)$ & $0.86 \pm 0.08$ & 0.98 & $172 *$ & $1.62(1.59-1.65)$ & $0.44 \pm 0.01$ & 1.00 & 184 \\
\hline $\mathbf{P 2}+\mathbf{S U W}$ & $0.66(0.62-0.71)$ & $0.99 \pm 0.05$ & 0.99 & 85 & 1.39 (1.37-1.41) & $0.54 \pm 0.01$ & 0.99 & 178 \\
\hline
\end{tabular}

* Significant at the 0.05 probability level.

$\uparrow$ Numbers in parentheses are standard errors about the mean.

$\uparrow$ No sorption measured.

and sorption coefficients, $K_{\mathrm{f}}, 1 / n_{\mathrm{f}}$, and $K_{\mathrm{oc}}\left(K_{\mathrm{f}}\right.$ normalized to soil organic C content) were calculated (Table 3 ). Sorption coefficient, $1 / n_{\mathrm{f}}$, was similar for the three soils, thus allowing comparison of $K_{\mathrm{f}}$ values. Simazine sorption increased by a factor of 2.5 upon amendment with SOA. The $K_{\mathrm{oc}}$ values did not reduce variability between soils, which occurs when organic matter is the main soil component affecting sorption (Green and Karickhoff, 1990). The highest value corresponded to the higher sorptive system, $\mathrm{P} 2+\mathrm{SOA}$.

No sorption of 2,4-D was measured on Soil P2 under the conditions studied, but 2,4-D did sorb on amended soils. Isotherms are L-type, which indicates that there is a limit in sorption capacity as solution concentration increases (Giles et al., 1960). At low solution concentration, equilibrium concentrations were found to be slightly greater than the respective initial concentrations (Fig. 1b), which has been attributed to adsorption of water by the soil surfaces in preference to the 2,4-D anions (Weber et al., 1965; Haque and Sexton, 1968). At the $\mathrm{pH}$ of the soils studied (Table 2), 2,4-D is predominantly in the anionic form and would be repelled by negatively charged soil surfaces (Celis et al., 1999). Sorption coefficients (Table 3) increase in the order P2 + LOA $<$ $\mathrm{P} 2+\mathrm{SUW}<\mathrm{P} 2+\mathrm{SOA}$. As with simazine, $K_{\mathrm{f}}$ and $K_{\mathrm{oc}}$ values are higher in $\mathrm{P} 2+\mathrm{SOA}$ soil.

The very similar organic matter content of the amended Soils P2 + LOA and P2 + SOA (Table 2), their very different sorption behavior (Table 3), and the differences in calculated Koc between original Soil P2 and amended soils for each herbicide (Table 3), indicate that sorption is a complex interaction. The quality of organic matter, the contribution of mineral surfaces, and the intimate association between organic matter and soil mineral colloids (which affects the contribution of mineral colloids), all influence sorption behavior (Mingelgrin and Gerstl, 1983; Benoit et al., 1996; Celis et al., 1998b). Natural organic matter in soil is not homogeneous in composition, degree of humification, or physicochemical properties (Xing, 1997). Consequently, when soil organic matter is exogenous in origin (i.e., soil amendment), variability in sorption capacity of soils is expected. Although of same origin (olive oil-mill waste), the higher amount of DOC and different structural characteristics of LOA compared with SOA and SUW, should contribute to this lack of homogeneity (Baskaran et al., 1996).

The lower sorption of simazine in P2 + LOA soil can be attributed to interactions between small DOC molecules and soil surfaces. In the case of simazine, the increase in soil sorption sites upon amendment would be counterbalanced by the competition between DOC molecules of LOA and simazine molecules, rendering similar sorption as the original Soil P2. In the case of 2,4-D, although sorption is higher in $\mathrm{P} 2+\mathrm{SOA}$ and $\mathrm{P} 2+$ SUW than in P2 + LOA, the amendment with LOA generates sorption sites in soil, since no sorption was measured in the case of the unamended P2 soil. These differences can be explained considering the different sorption mechanisms of the two herbicides. Simazine, as other $s$-triazines, sorbs on solid organic matter and on montmorillonite but not on $\mathrm{Fe}$ oxides (Celis et al., 1998b). Simazine sorbs mainly by H-bonding or proton transfer to organic matter, while sorption on clay minerals takes place as protonated species or as molecular species on hydrophobic microsites of montmorillonite surfaces (Celis et al., 1997). The herbicide, 2,4-D, sorbs on organic matter, does not sorb on montmorillonite (unless solution $\mathrm{pH}$ is low) and does sorb on $\mathrm{Fe}$ oxide through electrostatic interactions between negatively charged carboxylic groups and positively charged Fe oxide surface (Celis et al., 1998b; Cox et al., 2000). Previous work has shown that DOC of LOA blocks montmorillonite sorption sites to a higher extent than Fe oxide surfaces, consequently, competing with simazine molecules for sorption sites to a greater extent than with 2,4-D (Cox et al., 2000).

\section{Incubation Studies}

The amounts of simazine extracted from P2 + SUW were slightly reduced when compared with unamended $\mathrm{P} 2$, whereas in the case of $\mathrm{P} 2+\mathrm{LOA}$ and $\mathrm{P} 2+\mathrm{SOA}$ disappearance from soil extracts is much faster, $\sim 85 \%$ remaining after $28 \mathrm{~d}$ compared with $\mathrm{P} 2$ and $\mathrm{P} 2+\mathrm{SUW}$. Extrapolated half-lives are one-third of that in $\mathrm{P} 2$ soil (Fig. 2a and Table 4). The increase in organic C content upon amendment has been shown to promote biodegradation by enhancing microbial populations and activities (Felsot and Shelton, 1993; Guo et al., 1993; Topp et al., 1996; Cox et al., 1997; Gan et al., 1998). The lower amounts of simazine extracted from P2 + LOA and $\mathrm{P} 2+\mathrm{SOA}$ as compared with $\mathrm{P} 2+\mathrm{SUW}$, can be attributed to the lower organic matter and DOC content of P2 + SUW (Table 2), and to some toxic effect of heavy metals, more abundant in SUW residue (Table 1) than in agricultural origin SOA or LOA, on soil microorganisms (Häni et al., 1996; Giller et al., 1999).

In contrast to simazine, 2,4-D followed a sigmoidal rate of degradation in Soils $\mathrm{P} 2, \mathrm{P} 2+\mathrm{SOA}$ and $\mathrm{P} 2+$ 

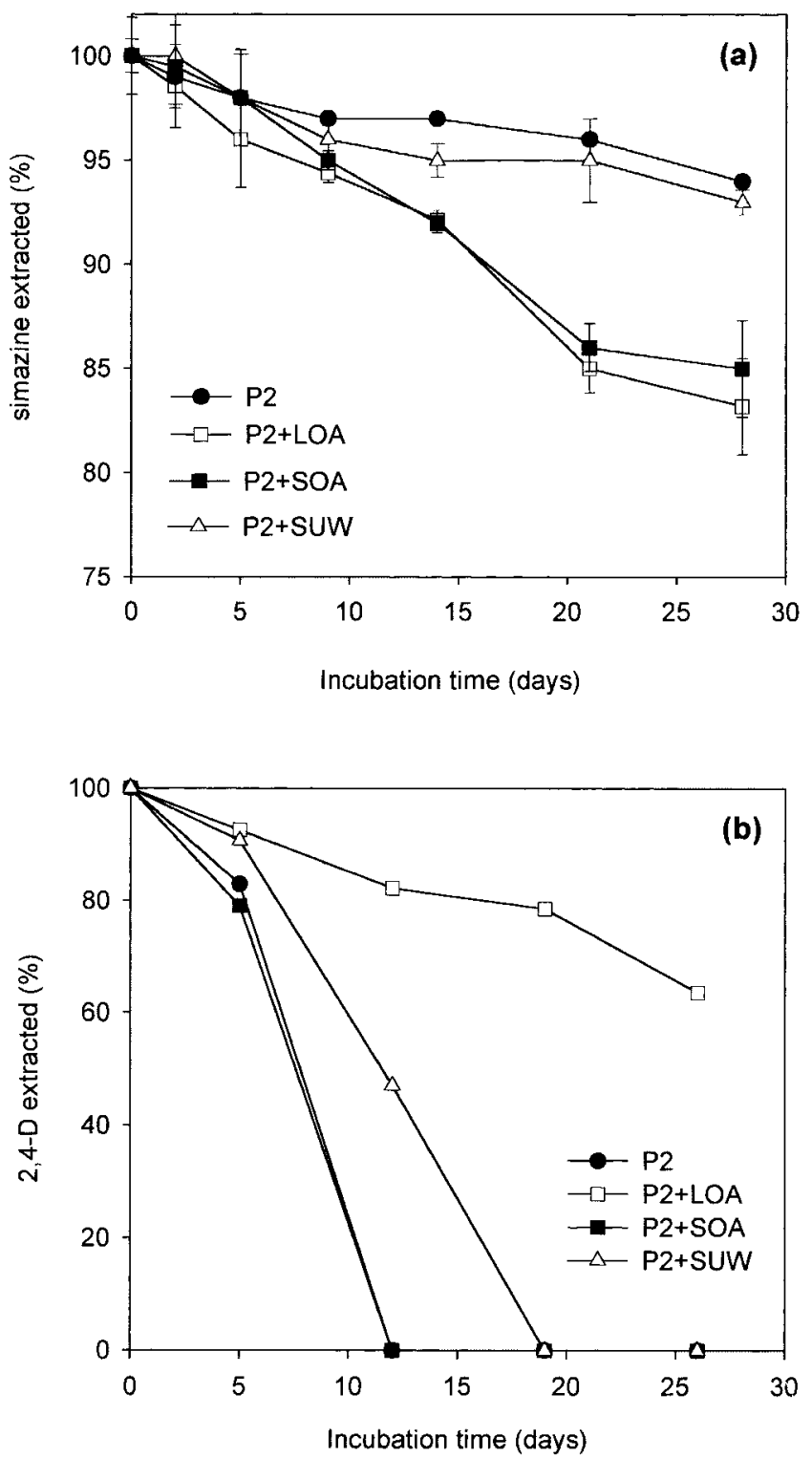

Fig. 2. (a) Simazine and (b) 2,4-D dissapation curves in unamended sandy soil (Soil P2) and amended sandy soil plus liquid organic amendment (P2 + LOA), sandy soil plus solid organic amendment (P2 + SOA), and sandy soil plus solid urban waste (P2 + SUW).

SUW (Fig. 2b), typical of pesticides used as microbial growth substrate (Kearney et al., 1997). Only 2,4-D degradation in $\mathrm{P} 2+$ LOA followed first-order kinetics with a calculated half-life of $43 \mathrm{~d}$ (Table 4). After a $20 \mathrm{~d}$ incubation period, no 2,4-D was extracted from P2, P2 + SOA or P2 + SUW soil, whereas in the P2 + LOA soil, even after a 25 -d incubation period nearly $70 \%$ of the initially applied 2,4-D was extractable from soil. In general, 2,4-D dissipation rates have been reported to be lowest on the soil on which sorption was greatest (Johnson et al., 1995), which does not agree with results obtained in sorption studies (Table 3 ). This very high persistence of 2,4-D in P2 + LOA amended soil can be attributed to a toxic effect of the LOA on soil bacteria or to DOM-2,4-D interactions, which protects herbicide from degradation. The latter will be discussed in the section below.

\section{Soil Column Studies}

\section{Soil Pore-size Distribution}

Total cumulative soil pore volume was reduced upon OA (Figure 3), because of a reduction of large-size or conducting pores $(>1 \mu \mathrm{m})$, as shown in Table 5. Solid OAs (SOA and SUW) reduced soil porosity to a greater extent as compared with LOA, and this reduction was more significant in the case of the SUW, of lower DOC (Table 5). These data suggest that nonsoluble organic matter cements and aggregates together soil particles, blocking large-size conducting pores (Tisdall and Oades, 1982). In contrast, soil pores in the 1 - to $0.01-\mu \mathrm{m}$ range increased in the amended soils, especially in the case of the liquid amendment LOA, which has higher DOC content. Similar results were observed in a clay soil amended with olive-mill wastewater (Cox et al., 1997).

\section{Herbicide Leaching}

Simazine was detected in leachates from original Soil P2 slightly earlier than in leachates from amended soils, and the maximum simazine concentration was much higher (Figure 4a). Lower sorption will lead to less retardation and, hence, earlier breakthrough (Gamendinger et al., 1993; Beck et al., 1993). The similar breakthrough curves (BTCs) of simazine on P2 + LOA and P2 + SOA of different sorption capacity (Table 3 ) and similar half-lives (Table 4), indicate that degradation affects leaching of simazine to a higher extent than sorption processes. Simazine BTC in Soil P2 + SUW was between those corresponding to P2 and P2 amended with LOA or SOA, although $K_{\mathrm{f}}$ values are similar to those corresponding to P2 and P2 + LOA (Table 3). The higher persistence of simazine in P2 + SUW, when compared with the other amended soils (Table 4), can explain this different leaching behavior. However, simazine BTCs in P2 and P2 + SUW soils of similar sorption

Table 4. Extrapolated simazine and 2,4-D half lives $\left(t_{1 / 2}, d\right)$ in P2 soil and amended soils P2-LOA and P2-SOA. P2 soil plus liquid organic amendment, P2 soil plus soil organic amendment (P2 + SOA), and P2 soil plus solid urban waste (P2 + SUW).

\begin{tabular}{|c|c|c|c|c|c|c|c|c|}
\hline \multirow[b]{2}{*}{ Herbicide } & \multicolumn{2}{|l|}{ P2 } & \multicolumn{2}{|c|}{ P2 + LOA } & \multicolumn{2}{|c|}{ P2 + SOA } & \multicolumn{2}{|c|}{$\mathbf{P 2}+\mathbf{S U W}$} \\
\hline & $t_{1 / 2}$ & $R^{2}$ & $t_{1 / 2}$ & $R^{2}$ & $t_{1 / 2}$ & $R^{2}$ & $t_{1 / 2}$ & $R^{2}$ \\
\hline & d & & d & & d & & d & \\
\hline $\begin{array}{l}\text { Simazine } \\
\text { 2,4-D }\end{array}$ & $\begin{array}{c}362(326-408) \dagger \\
-\end{array}$ & $\begin{array}{c}0.94 \\
-\end{array}$ & $\begin{array}{c}102 * *(95-109) \\
43(38-49)\end{array}$ & $\begin{array}{l}0.98 \\
0.96\end{array}$ & $\begin{array}{c}108 *(100-116) \\
-\end{array}$ & $\begin{array}{c}0.98 \\
-\end{array}$ & $\begin{array}{c}272(236-321) \\
-\end{array}$ & $\begin{array}{c}0.90 \\
-\end{array}$ \\
\hline
\end{tabular}

* Significant at the 0.05 probability level.

** Significant at the 0.01 probability level.

$\uparrow$ Numbers in parentheses are standard errors about the mean. 

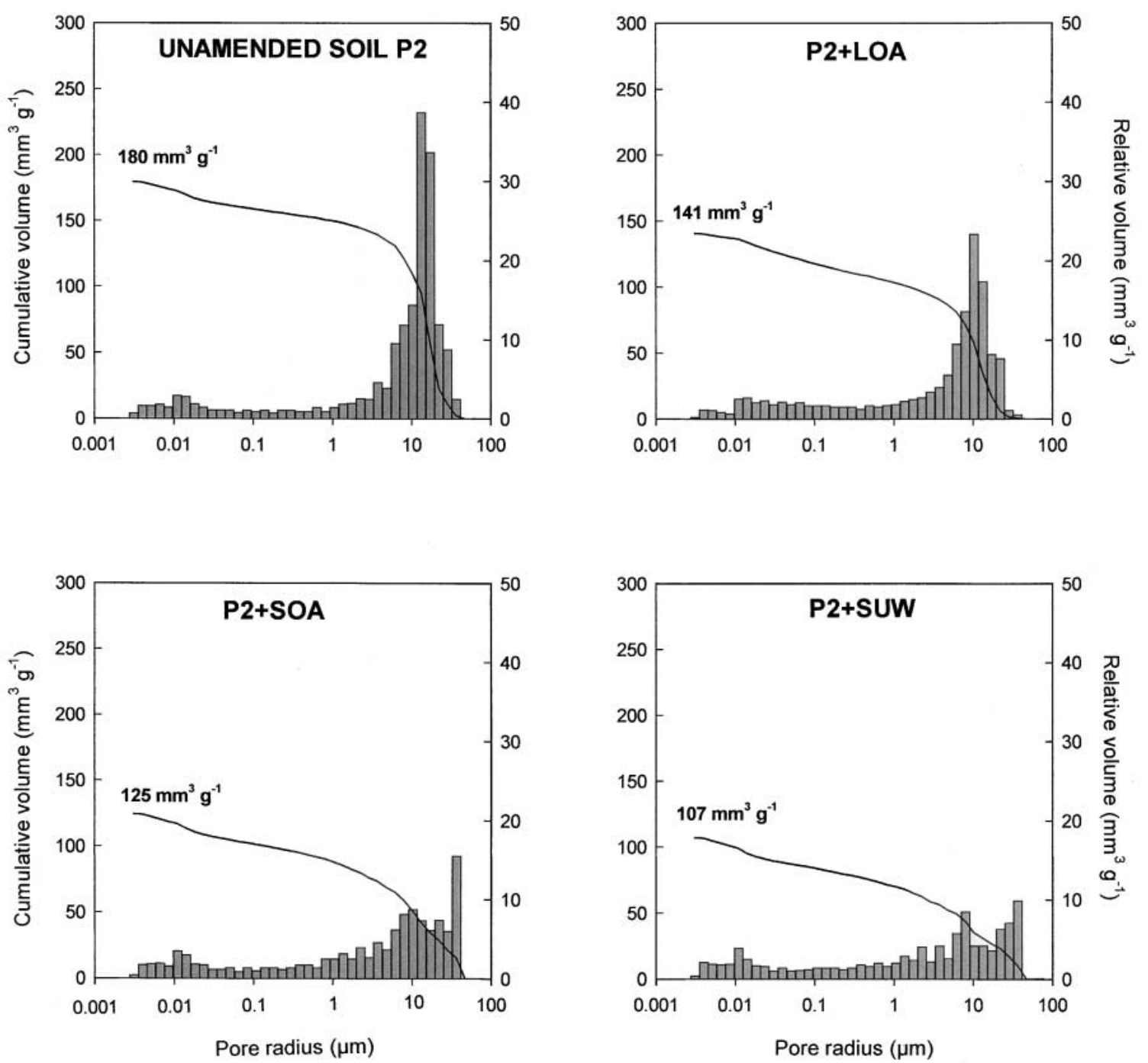

Fig. 3. Relative and cumulative $\mathrm{Hg}$ pore volume for unamended sandy soil (Soil P2) and amended sandy soil plus liquid organic amendment (P2 + LOA), sandy soil plus solid organic amendment (P2 + SOA), and sandy soil plus solid urban waste (P2 + SUW).

and half-life (Fig. 1a, Tables 3 and 4), were very different; simazine BTC in P2 + SUW was broader, the maximum was lower and slightly shifted to the right, and tailing was more pronounced than in $\mathrm{P} 2$ soil.

The processes retarding pesticide leaching occur in the transition between mobile and immobile water phases, where the interaction between soil solution and soil surfaces through diffusion, sorption, and degradation processes takes place (Doran, 1987; Walker and Welch, 1989; Beck et al., 1993). Mercury porosimetry studies have shown a greater reduction in large-size conducting pores upon SUW amendment compared with the other OA (Figure 3, Table 5). This decrease could result in an increase in contact time of the herbicide with soil surfaces, enhancing sorption and degradation processes and, consequently, rendering differences in leaching behavior greater than those suggested from the small differences in sorption and degradation observed between P2 and P2 + SUW soils (Cox et al., 1997).

The 2,4-D moved more rapidly through soil columns than simazine (Fig. 4b). Differences between 2,4-D leaching in $\mathrm{P} 2$ and amended Soils $\mathrm{P} 2+\mathrm{SOA}$ and $\mathrm{P} 2+$
SUW can be attributed to higher sorption of 2,4-D on these soils, and also to a reduction in large-size conducting pores (Table 5), which increases contact time with soil surfaces favoring degradation. Leaching of 2,4-D was not reduced upon amendment with LOA. A maximum of the BTC and total amounts leached were much higher in $\mathrm{P} 2+$ LOA soil. As indicated earlier, 2,4-D degradation in P2 + LOA soil, with greater DOC (Table 2 ), is much slower than in P2 or other amended soils

Table 5. Pore volumes for different pore-size ranges of the original soil and amended soil obtained by $\mathrm{Hg}$ porosimetry.

\begin{tabular}{|c|c|c|c|c|c|}
\hline \multirow[b]{2}{*}{ Soil } & \multicolumn{5}{|c|}{ Pore volume, $\mathbf{m m}^{3} \mathrm{~g}^{-1}$} \\
\hline & $>1 \mu \mathrm{m}$ & 1-0.1 $\mu \mathrm{m}$ & $0.1-0.01 \mu \mathrm{m}$ & $<0.01 \mu \mathrm{m}$ & Total \\
\hline $\mathbf{P 2}$ & 150 & 9 & 14 & 7 & 180 \\
\hline $\mathbf{P 2}+\mathbf{L O A} \dagger$ & $104^{*}$ & 14 & 19 & 4 & 141 \\
\hline $\mathbf{P 2}+$ SOA & $89 *$ & 13 & 16 & 7 & $125^{*}$ \\
\hline $\mathbf{P 2}+\mathbf{S U W}$ & $70 * *$ & 14 & 15 & 8 & $107 *$ \\
\hline
\end{tabular}

* Significant at the 0.05 probability level. ** Significant at the 0.01 probability level. $\dagger$ P2 soil plus liquid organic amendment. \$ P2 soil plus solid organic amendment. $\S$ P2 soil plus solid urban waste. 

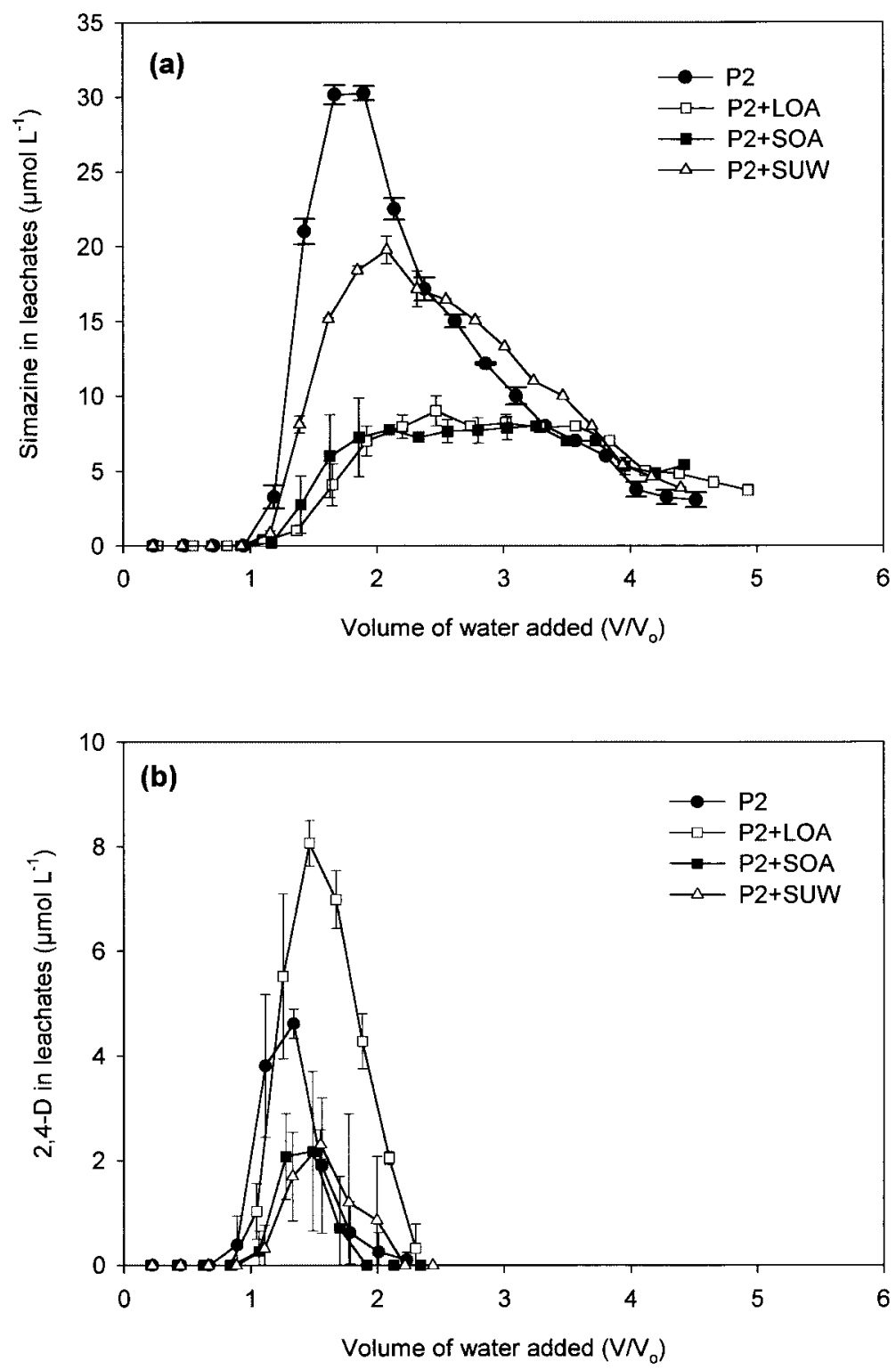

Fig. 4. (a) Simazine and (b) 2,4-D breakthrough curves in unamended sandy soil (Soil P2) and amended sandy soil plus liquid organic amendment $($ P2 + LOA), sandy soil plus solid organic amendment (P2 + SOA), and sandy soil plus solid urban waste (P2 + SUW).

(Fig. 2b). The degree to which DOM will complex with organic chemicals depends on the nature and source of the DOM (Nelson et al., 1998). The herbicide-DOM interaction might be, in part, responsible for the greater 2,4-D persistence in $\mathrm{P} 2+\mathrm{LOA}$ and, consequently, for greater leaching. As discussed above, dialysis experiment results strongly indicated that the small DOM molecules of LOA are able to associate with 2,4-D molecules (probably through electrostatic forces) but not with simazine. Most likely, facilitated transport of 2,4-D in $\mathrm{P} 2+$ LOA took place as a consequence of the formation of stable complexes which also protected herbicide molecules from soil microorganisms.

\section{CONCLUSIONS}

Organic amendments modify leaching behavior of herbicides by affecting soil physical properties such as soil porosity, sorption, and persistence. Knowledge of the nature of the exogenous organic $\mathrm{C}$ is essential, in particular the amount of DOC, to determine the potential leaching of pesticides. Consequently, the general idea that organic matter reduces the leaching potential of herbicides is not always true. Although difficult to extrapolate to field, our results indicate that simultaneous application of 2,4-D and LOA can increase the risk of groundwater contamination by this herbicide because of its high stability in the P2 + LOA amended soil.

\section{ACKNOWLEDGMENTS}

This work has been partially supported by Junta de Andalucía through Research Group RNM124 and by CICYT through the project AMB96-0445-CO2-02.

\section{REFERENCES}

Agbekodo, K.M., B. Legube, and S. Dard. 1996. Atrazine and simazine removal mechanisms by nanofiltration: Influence of natural organic matter concentration. Water Res. 30:2535-2542. 
Barriuso, E., U. Baer, and R. Calvet. 1992. Dissolved organic matter and adsorption-desorption of dimefuron, atrazine and carbetamide by soils. J. Environ. Qual. 21:359-367.

Barriuso, E., S. Houot, and C. Serra-Wittling. 1996. Influence of compost addition to soil on the behaviour of herbicides. Pestic. Sci. 49:65-75.

Baskaran, S., N.S. Bolan, A. Rahman, and R.W. Tilman. 1996. Effect of exogenous carbon on the sorption and movement of atrazine and 2,4-D by soils. Aust. J. Soil Res. 34:609-622.

Beck, A.J., A.E. Johnston, and K.C. Jones. 1993. Movement of nonionic organic chemicals in agricultural soils. Crit. Rev. Environ. Sci. Technol. 23:219-248.

Benoit, P., E. Barriuso, S. Houot, and R. Calvet. 1996. Influence of the nature of soil organic matter on the sorption-desorption of 4chlorophenol, 2,4-dichlorophenol and the herbicide 2,4-dichlorophenoxyacetic acid (2,4-D). Europ. J. Soil Sci. 47:567-578.

Businelli, D. 1997. Pig slurry amendment and herbicide coapplication effects on s-triazine mobility in soil: An adsorption-desorption study. J. Environ. Qual. 26:102-108

Celis, R., J. Cornejo, M.C. Hermosín, and W.C. Koskinen. 1997. Sorption-desorption of atrazine and simazine by model soil colloidal components. Soil Sci. Soc. Am. J. 61:436-443.

Celis, R., E. Barriuso, and S. Houot. 1998a. Sorption and desorption of atrazine by sludge-amended soil: Dissolved organic matter effects. J. Environ. Qual. 27:1348-1356.

Celis, R., J. Cornejo, M.C. Hermosín, and W.C. Koskinen. 1998b. Sorption of atrazine and simazine by model associations of soil colloids. Soil Sci. Soc. Am. J. 62:165-171.

Celis, R., M.C. Hermosín, L. Cox, and J. Cornejo. 1999. Sorption of 2,4dichlorophenoxy-acetic acid by model particles simulating naturally occurring soil colloids. Environ. Sci. Technol. 33:1200- 1206.

Chiou, C.T. 1989. Theoretical considerations of the partition uptake of nonionic organic compounds by soil organic matter.p.1-29 In Reactions and Movement of Organic Chemicals in Soils. SSSA Spec. Publ. No. 22. ASA and SSSA, Madison, WI.

Cox, L., R. Celis, M.C. Hermosín, A. Becker, and J. Cornejo. 1997. Porosity and herbicide leaching in soils amended with olive-mill waste water. Agric. Ecosys. Environ. 65:151-161.

Cox, L., W.C. Koskinen, and P.Y. Yen. 1998. Changes in sorption of imidacloprid with incubation time. Soil Sci. Soc. Am. J. 62:342-347.

Cox, L., R. Celis, R., M.C. Hermosín, J. Cornejo, A. Zsolnay, and K. Keller. 2000. Effect of organic amendments on herbicide sorption as related to the nature of the dissolved organic matter. Environ. Sci. Technol. 34:4600-4605.

Doran, J.W. 1987. Microbial biomass and mineralizable nitrogen distribution in no-tillage and plowed soils. Biol. Fertil. Soils 5:68-75.

Felsot, A.S., and D.R. Shelton. 1993. Enhanced biodegradation of soil pesticides: Interactions between physicochemical processes and microbial ecology. p. 227-251 In Sorption and Degradation of Pesticides and Organic Chemicals in Soils. SSSA Spec. Publ. 32. ASA and SSSA, Madison, WI.

Felsot, A.S., and E.K. Dzantor. 1995. Effect of alachlor concentration and an organic amendment on soil dehydrogenase activity and pesticide degradation rate. Environ. Toxicol. Chem. 14:23-28

Gamerdinger, A.P., K.C. Dowling, and A.T. Lemley. 1993. Miscible displacement and theoretical techniques for simultaneous study of pesticide sorption and degradation during transport. p. 115-123. In Sorption and degradation of pesticides and organic chemicals in soils. SSSA Spec. Publ. no. 32, ASA and SSSA, Madison, WI.

Gan, J., S.R. Yates, S. Papiernik, and D. Crowley. 1998. Application of organic amendments to reduce volatile pesticide emissions from soil. Environ. Sci. Technol. 32:3094-3098.

Giles, C.H., S.N. McEwan, S.N. Nakhwa, and D. Smith. 1960. Studies in adsorption. Part XI. A system of classification of solution adsorption isotherms and its use in diagnosis of adsorption mechanisms and in measurement of specific surface area in solids. J. Chem. Soc. 3:3973-3993.

Giller, K.E., E. Witter, and S.P. McGrath. 1999. Assessing risks of heavy metal toxicity in agricultural soils: Do microbes matter? Human and Ecological Risk Assessment 5:683-689.
Goodrich, J.A., B.J. Lykins, Jr., and R.M. Clark. 1991. Drinking water from agriculturally contaminated groundwater. J. Environ. Qual. 20:707-717.

Green, R.E., and S.W. Karickhoff. 1990. Sorption estimates for modeling. p. 79-101 In H.H. Cheng (ed.) Pesticides in the soil environment: Processes, impacts, and modeling. SSSA Book Ser. 2. SSSA, Madison, WI.

Guo, L., T.J. Bicki, A.S. Felsot, and T.D. Hinesly. 1993. Sorption and movement of alachlor in soil modified by carbon-rich wastes. J. Environ. Qual. 22:186-194.

Häni, H., A. Siegenthaler, and T. Candinas. 1996. Soil effects due to sewage sludge application in agriculture. Fertilizer Res. 43:149-156.

Haque, R., and R. Sexton. 1968. Kinetic and equilibrium study of the adsorption of 2,4-dichlorophenoxy acetic acid on some surfaces. J. Colloid Interface Sci. 27:818-827.

Hermosín, M.C., and J. Cornejo. 1993. Binding Mechanism of 2,4dichlorophenoxyacetic acid by organo-clays. J. Environ. Qual. 22: 325-331.

Johnson, W.G., T.L. Lavy, and E.E. Gbur. 1995. Persistence of triclopyr and 2,4-D in flooded and nonflooded soils. J. Environ. Qual. 24:493-497.

Kearney, P.C., D.R. Shelton, and W.C. Koskinen. 1997. p. 419-451. Soil chemistry of pesticides In Kirk-Othmer Enciclopedia of Chemical Technology, 4th ed., Vol. 22.

Khan, S.U. 1980. Pesticides in the soil environment. Elsevier Sci. Publ. Comp, New York.

Koskinen, W.C., and S.S. Harper. 1990. The retention process: Mechanisms. p. 51-77. In H.H. Cheng (ed) Pesticides in the soil environment: Processes, impact, and modeling. SSSA Book Ser. 2. SSSA, Madison, WI.

Lee, D.-Y., W.J. Farmer, and Y. Aochi. 1990. Sorption of napropamide on clay and soil in the presence of dissolved organic matter. J. Environ. Qual. 19:567-573.

Mingelgrin, U., and Z. Gerstl. 1983. Reevaluation of partitioning as a mechanism of nonionic chemicals adsorption in soils. J. Environ. Qual. 12:1-11.

Nelson, D.W., and L.E. Sommers. 1982. Total carbon, organic carbon, and organic matter. p. 539-579. In A.L. Page (ed.), Methods of soil analysis. Pt 2. 2nd ed. ASA and SSSA, Madison, WI.

Nelson, S.D., J. Letey, W.J. Farmer, C.F. Williams, and M. Ben-Hur. 1998. Facilitated transport of napropamide by dissolved organic matter in sewage sludge-amended soil. J. Environ. Qual. 27:11941200.

Ritter, W.F., R.W. Scarborough, and A.E.M. Chirnside. 1994. Contamination of groundwater by triazines, metolachlor and alachlor. J. Contam. Hydrol. 15:73-92.

Sloan, J.J., R.H. Dowdy, and M.S. Dolan. 1998. Recovery of biosolidsapplied heavy metals sixteen years after application. J. Environ. Qual. 27:1312-1317.

Tisdall, J.M., and J.M. Oades. 1982. Organic matter and water stable aggregates in soils. J. Soil Sci. 33:141-163.

Topp, E., L. Tessier, and E.G. Gregorich. 1996. Dairy manure incorporation stimulates rapid atrazine mineralization in an agricultural soil. Can. J. Soil Sci. 76:403-409.

Walker, A., and S.J. Welch. 1989. The relative movement and persistence in soil of chlorsulfuron, metsulfuron-methyl and triasulfuron. Weed Res. 29:375-383.

Wauchope, R.D. 1978. The pesticide content of surface water draining from agricultural fields-A review. J. Environ. Qual. 7:459-472.

Weber, J.B., P.W. Perry, and R.P. Upchurch. 1965. The influence of temperature and time on the adsorption of paraquat, diquat, 2,4-D and prometone by clays, charcoal, and an anion-exchange resin. Soil Sci. Soc. Am. Proc. 29:678-688.

Worthing, C.R., and R.J. Hance. 1991. The Pesticide manual. BCPC, Surrey, UK.

Xing, B. 1997. The effect of the quality of soil organic matter on sorption of naphthalene. Chemosphere 35:633-642.

Zsolnay, A. 1992. Effect of an organic fertilizer on the transport of the herbicide atrazine in soil. Chemosphere 24:663-669. 